The Open Construction and Building
Technology Journal
CrossMark
Content list available at: www.benthamopen.com/TOBСТ $/$

RESEARCH ARTICLE

\title{
Study on Mechanical Properties and Constitutive Equation of Hybrid Fiber Reinforced Cementitious Composites Under Static Loading
}

\author{
Huixian Yang ${ }^{1}$, Jing $\mathrm{Li}^{1,2, *}$ and Yansheng Huang ${ }^{1,2}$ \\ ${ }^{I}$ School of Civil Engineering and Transportation, South China University of Technology, Guangzhou 510640, P.R. \\ China \\ ${ }^{2}$ State Key Laboratory of Subtropical Building Science, Guangzhou 510640, P.R. China
}

Received: December 17, 2015

Revised: July 09, 2016

Accepted: August 02, 2016

\begin{abstract}
The Quasi-static mechanical properties of hybrid fiber (steel fiber and Polyvinyl alcohol (PVA) fiber) reinforced cementitious composites (HFRCC(SP)) were investigated by compressive and tensile experiments. The compressive strength, peak strain, elastic modulus and tensile strength are studied as compared with that of engineered cementitious composite (ECC). Study results indicate that steel fibers can improve the compressive and tensile strength of HFRCC(SP) but the peak strain of HFRCC(SP) decreases. The formulas modified based on codes are proposed to calculate compressive peak strain, elastic modulus and tensile strength. The relationship between tensile strain at peak load and tensile strength of HFRCC with different volume fractions of polyethylene fiber and steel fiber were studied and the tensile stress-strain relation was presented. The parameters $k_{1}$ and $k_{2}$ of constitutive formulas for fiber reinforced high strength concrete presented by Mansur are modified to describe the stress-strain curve of HFRCC(SP), the modified formulas show good agreement with the experimental results.
\end{abstract}

Keywords: Cementitious composites, Constitutive equation, Experimentation investigation, Hybrid fiber, Mechanical properties, Static loading.

\section{INTRODUCTION}

Cement-based materials are always suffer the compressive loading for its disadvantages, such as low tensile strength and highly brittle. Fiber reinforced cementitious composites (FRCC) process more advantages than concrete such as high compressive strength, high tensile strength and high toughness. The researches show that different kinds of fiber can reinforce the certain mechanical properties of FRCC, adding high modulus fibers like steel fibers or carbon fibers can improve tensile strength but show low toughness [1] and adding low modulus fibers like polyvinyl alcohol (PVA) fiber or Polypropylene (PE) fiber can improve toughness but show low tensile strength [2].

Engineered cementitious composite (ECC), the PVA fiber or PE fiber reinforced cementitious composites exhibit multiple cracking behavior and tensile strain hardening [3], it is widely investigated, but for the low modulus of fibers, ECC shows low tensile strength. It has been shown recently that hybrid fiber (steel and PE fiber) reinforced cementitious composites(HFRCC(SPE)) possess high ultimate tensile strain and high tensile strength [4], HFRCC(SPE) was used to strengthened masonry walls and the out- of-plane resistance of reinforced masonry walls were improved [5], HFRCC(SPE) is also an ideal material for subjecting dynamic loads [6]. However, the study of FRCC was focused on ECC and the tensile mechanical properties of HFRCC. The compressive mechanical properties of HFRCC with PVA fiber and steel fiber are few. Moreover, the study of tensile and compressive stress-strain relation of HFRCC are rarely reported. The study of the paper can promote the application and research of HFRCC. In this research, static mechanical properties of HFRCC that contains $0.75 \%$ steel and $1.25 \%$ PVA fibers are studied. The experiment results show that

\footnotetext{
* Address correspondence to this author at the School of Civil Engineering and Transportation, South China University of Technology, Guangzhou 510640, P.R. China; E-mail 278334902@qq.com
} 
HFRCC processes the optimal balance between tensile strength and toughness. The tensile and compressive constitutive formulas of HFRCC are presented.

\section{EXPERIMENTAL PROGRAM}

The contents of experimental program may have similarities with the paper $[7,8]$ which has been published by the authors but the dimension of specimens and the testing procedures are different in this paper.

\subsection{Materials}

The Portland cement (C) 42.5 produced by Guangzhou Yuebao Cement Plant China was used in this study. The Fly Ash (FA) was class I fly ash produced by the Foshang heat and power plant. Fine silica sand (SS) with maximum grain size of $0.25 \mathrm{~mm}$ and a mean size of $0.11 \mathrm{~mm}$ was used. The PVA fiber provided by Kuraray Ltd Co. Japan and the steel fiber provided by Bekaert Company were used. Steel fiber and PVA fiber are shown in Fig. (1). The properties of fibers are listed in Table 1. The High Range Water Reducing Admixture (HRWRA) with solid content of $40 \%$ was used.

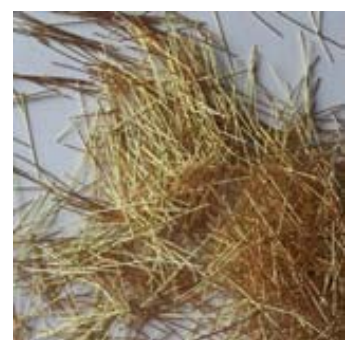

(a) steel fiber

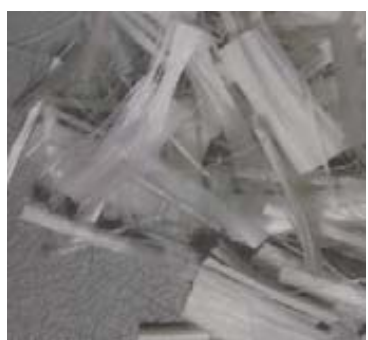

(b) PVA fiber

Fig. (1). Steel fiber and PVA fiber.

Table 1. Properties of fibers.

\begin{tabular}{|c|c|c|c|c|}
\hline $\begin{array}{c}\text { Fiber } \\
\text { type }\end{array}$ & $\begin{array}{c}\text { Length/ } \\
\mathbf{m m}\end{array}$ & $\begin{array}{c}\text { Diameter/ } \\
\mathbf{m m}\end{array}$ & $\begin{array}{c}\text { Tensile } \\
\text { Strength/ } \\
\mathbf{M P a}\end{array}$ & $\begin{array}{c}\text { Young's Modulus/ } \\
\text { GPa }\end{array}$ \\
\hline steel & 13 & 0.2 & 2000 & 220 \\
\hline PVA & 12 & 0.038 & 1600 & 40 \\
\hline
\end{tabular}

\subsection{Mixing Proportion and Specimen Casting}

In this research, the HFRCC(SP) reinforced by PVA and steel fibers are studied. The volume fraction of steel fibers is $0.75 \%$ and PVA fibers is $1.25 \%$, the mix proportion of the other components are listed in Table 2.

Table 2. Mix Proportion of HFRCC $\left(\mathrm{kg} / \mathrm{m}^{3}\right)$.

\begin{tabular}{|c|c|c|c|c|}
\hline Sand & Fly ash & Cement & Water & HRWRA \\
\hline 462 & 693 & 578 & 319 & 7.5 \\
\hline
\end{tabular}

The focused concrete mixer with 60-liter capacity was used to mix and the HFRCC(SP) materials were mixed in the following sequence.

Firstly, cement, fly ash and sand were mixed for 2 minutes in a dry state. Then water and HRWRA were added and the mixture continued to mix for 3minutes. Finally, fibers were added, PVA fibers were added firstly and mixed for 2 minutes, then the steel fibers were added and mixed for 4 minutes, in order to make the fibers get a good dispersion, the fibers were added by hands slowly. The above mixing process took about 11 minute totally.

The quasi-static compressive specimens were casted into molds with the dimension of $\Phi 76 \times 152(\mathrm{~mm})$ and the tensile specimens were casted into molds with the dimension of $200 \times 40 \times 15(\mathrm{~mm})$, three specimens were prepared for each test. After 24 hours curing, the specimens were demoulded and cured under standard conditions for another 27 days. 


\subsection{Testing Procedures}

Quasi-static compressive tests were performed in the electro-hydraulic servo universal testing machine. The load sensor and dial indicators were used to collect loads and strains respectively, the setup of compressive test are shown in Fig. (2). The specimens were loaded under the strain rate of $6 \times 10^{-5} / \mathrm{s}$. The sans $10 \mathrm{~T}$ electronic universal testing machine was used for tensile tests. Two end of the specimen were strengthened with CFRP for avoiding damage before test. Loads were collected by the testing machine automatically. The compressive and tensile tests are shown in Figs. (3 and 4).

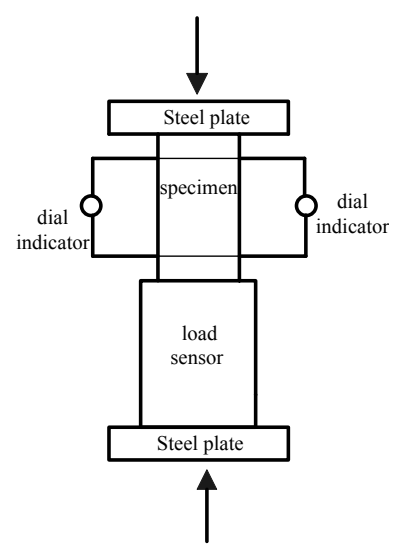

Fig. (2). Setup of compressive test.

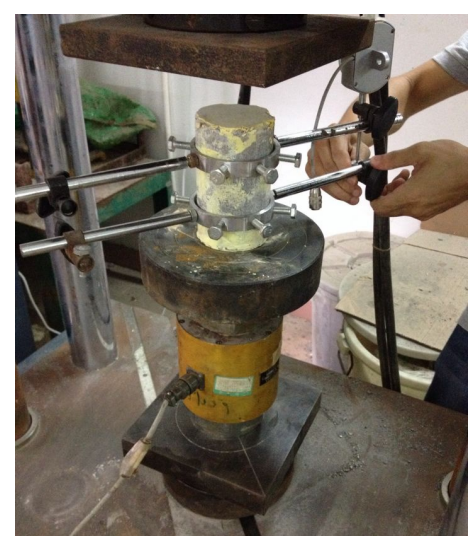

Fig. (3). Compressive test.

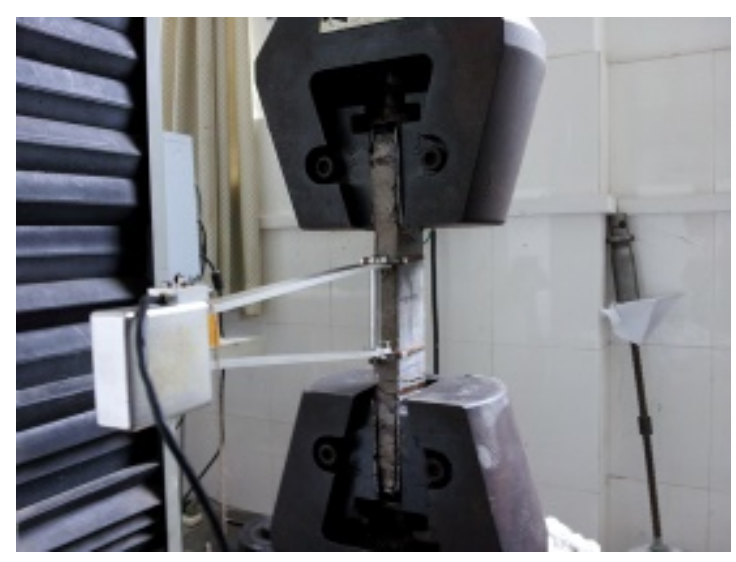

Fig. (4). Tensile test. 


\section{RESULTS AND DISCUSSION}

\subsection{Compressive Strength, Peak Strain and Elastic Modulus}

The compressive strength, peak strain and elastic modulus are three main values that depict the mechanical properties of HFRCC(SP) under compressive loading. At the ultimate load the response of the specimen depicted by the compressive strength and peak strain. From Table 3, the compressive strength of HFRCC(SP) is about $21 \%$ higher than ECC. The compressive peak strain of HFRCC(SP) and ECC are higher than concrete, the value of ECC is highest and the value of HFRCC(SP) is about $10 \%$ lower than that of ECC. Near the ultimate load, for lateral expansion of cementitious composites cracks will form and develop inside the specimen. Fibers aligned normal to the cracking direction will be resistant to cracks growth. Steel fiber has higher elastic modulus than that of PVA fiber and the resistance to cracks development of steel fiber is higher than that of PVA fiber. On the contrary, PVA fiber possesses better deformation capacity, therefore, the compressive peak strain is improved more obviously by the PVA fibers than steel fibers and the compressive strength can be improved obviously by steel fibers.

Table 3. Compressive strength, peak strain and elastic modulus.

\begin{tabular}{|c|c|c|c|}
\hline Specimen NO. & Compressive strength/MPa & Peak strain & Elastic modulus/MPa \\
\hline 1 & 77.45 & 0.003955 & 24253 \\
\hline 2 & 76.13 & 0.004058 & 22764 \\
\hline 3 & 81.03 & 0.004188 & 24847 \\
\hline Average value & 78.2 & 0.004067 & 20000 \\
\hline ECC [9] & 64.8 & 0.0045 & 39000 \\
\hline Concrete [10] & 70 & 0.0026 & \\
\hline
\end{tabular}

The elastic modulus reflects the initial response of the specimen under load. Elastic modulus of concrete is highest for containing coarse aggregate and elastic modulus of HFRCC(SP) is higher than that of ECC [9]. From Table 1, the elastic modulus of steel fiber is much larger than that of PVA fiber and can provide better stiffness.

Table 4. Relationship between peak strain, elastic modulus (MPa), tensile strength(MPa) and compressive strength(MPa).

\begin{tabular}{|c|c|c|c|c|}
\hline References & formula & $f_{c}, c_{m} / \mathrm{MPa}$ & calculated values & experimental values \\
\hline \multirow{3}{*}{ Eurocode $2^{[10]}$} & $\varepsilon_{c 1}=0.7 f_{c m}^{0.31}<0.0028$ & \multirow{6}{*}{78.2} & 0.00271 & 0.00358 \\
\hline & $f_{t}=2.12 \cdot \ln \left(1+\left(f_{c m} / 10\right)\right)$ & & 4.61 & 7.93 \\
\hline & $E_{c m}=22\left[\left(f_{c m}\right) / 10\right]^{0.3}$ & & 40796 & 23954 \\
\hline \multirow{2}{*}{ ACI 363R-92 ${ }^{[11]}$} & $E_{c}=3320 \sqrt{f_{c}^{\prime}}+6900$ & & 36259 & 23954 \\
\hline & $f_{s p}^{\prime}=0.59 \sqrt{f_{c}^{\prime}}$ & & 5.22 & 7.93 \\
\hline CEB-FIP $1990^{[12]}$ & $E_{c}=21500 \sqrt[3]{f_{c m} / f_{c m o}}$ & & 42675 & 23954 \\
\hline
\end{tabular}

note: $\varepsilon_{c l}$-peak strain, $E_{c}, E_{c m}$-elastic modulus, $f_{c}, f_{c m}-$ compressive strength of cylinder specimens, $f_{c m o},=10 \mathrm{MPa}, f_{t}, f_{s p}$-tensile strength of cylinder specimens.

The formulas recommended by Eurocode 2 [10], ACI 363R-92 [11] and CEB-FIP 1990 [12] are used to calculate the peak strain and elastic modulus. The calculated and experimental values are shown in Table 4. Clearly, the formulas are not suitable for HFRCC(SP). This is because the influence of fiber has not been referred to formulas. The volume fraction $V_{f}$ and the aspect ratio (length and diameter $(\mathrm{mm})$ of fiber) are the two most important factors used to characterize the behavior of fiber reinforced concrete [13], the revised formulas are recommended to calculate peak strain and elastic modulus and given as follows:

$$
\begin{aligned}
& \varepsilon=0.00024 \frac{V_{f} l}{\phi} f_{c m}^{0.31} \\
& E=29 \frac{V_{f} l}{\phi}\left(\frac{f_{c m}}{10}\right)^{0.3}
\end{aligned}
$$




$$
\frac{V_{f} l}{\phi}=\frac{V_{f, p} l_{f, p}}{\phi_{f, p}}+\frac{V_{f, s} l_{f, s}}{\phi_{f, s}}
$$

Where, $V_{f, P}, V_{f, s}$ the volume fraction of PVA fiber and steel fiber, respectively, $l_{f, p}, l_{f, s}$, - the length of PVA fiber and steel fiber, respectively, $\phi_{f, b}, \phi_{f, s},-$ the diameter of PVA fiber and steel fiber, respectively.

\subsection{Tensile Strength}

The cement-based materials are easy to emerge brittle failure for the low tensile strength. Adding fibers to reinforce cementitious composites (CC) is a good method to improve the tensile strength.

Tensile strengths of HFRCC(SP) are shown in Table 5, the average value is $7.93 \mathrm{MPa}$ about $58 \%$ higher than ECC. When the loading reaches the tensile strength of HFRCC(SP), the cracks are developing and the loads are translated to fibers. At the same strain steel fibers bear more loads than PVA fibers due to high elastic modulus. From Tables 3 and 5 , the compressive strength and tensile strength are increasing with the steel fibers adding and the effect is more obviously on tensile strength than that of compressive. From Table 4, the calculated value of tensile strength has great difference with experiment values, the revised formula is proposed to use to calculate the tensile strength and given as follow:

$$
f_{t}=0.2 \frac{V_{f} l}{\phi} \sqrt{f_{c m}}
$$

Table 5. Tensile strength (MPa) of HFRCC.

\begin{tabular}{|c|c|c|c|c|c|}
\hline $\begin{array}{c}\text { Specimen } \\
\text { NO. }\end{array}$ & $\mathbf{1}$ & $\mathbf{2}$ & $\mathbf{3}$ & average value & ECC $^{{ }^{19}}$ \\
\hline$f_{t} / \mathrm{MPa}$ & 7.79 & 8.47 & 7.52 & 7.93 & 5 \\
\hline
\end{tabular}

\subsection{Tensile Strain at Peak Load}

Engineered cementitious composite (ECC) exhibits high strain capacity, the tensile strain at peak load is about $3 \%$ to $5 \%$, but for the low stiffness of fiber, ECC shows low ultimate tensile strength. HFRCC exhibiting strain hardening behavior and high ultimate tensile strength for adding steel fibers are developed recently. Tensile strain hardening and multiple cracking behaviors of fiber reinforced cementitious composites containing different hybrid combinations of steel (ST) and polyethylene (PE) fibers are reported [4]. The tensile strain capacity at peak load decreases with increase in volume fractions of steel fibers can be seen in Fig. (5). In Fig. (6) the relationship between the tensile strain at peak load and tensile strength are shown. The tensile strain at peak load decreases with increase in tensile strength. The uniaxial tension test is difficult to implement for requiring a certain setup, in this paper the tensile strain is not measured. In order to study the relationship between tensile strength and tensile strain at peak load, the relative experimental data reported in the literature [4] are employed. The formulas are presented by fitting the experimental data.

$$
\begin{gathered}
\varepsilon_{c u, h}=a \sigma_{p, h}+b \\
a=c \frac{V_{f, P E} l_{f, P E}}{\phi_{f, P E}}+d \frac{V_{f, s} l_{f, s}}{\phi_{f, s}} \\
b=e \frac{V_{f, P E} l_{f, P E}}{\phi_{f, P E}}+f \frac{V_{f, s} l_{f, s}}{\phi_{f, s}} \\
c=-692.8 V_{f}^{2}+21.4 V_{f}-0.165 \\
d=-239.6 V_{f}^{2}+72.9 V_{f}-0.554 \\
e=3031 V_{f}^{2}-93.4 V_{f}+0.718
\end{gathered}
$$




$$
f=10440 V_{f}^{2}-3167 V_{f}+2.401
$$

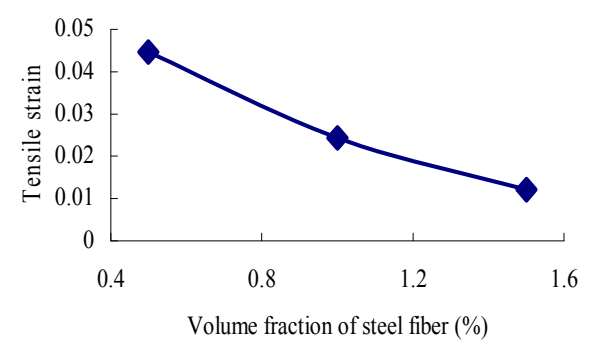

Fig. (5). The relationship between tensile strain and volume fraction of steel fiber.

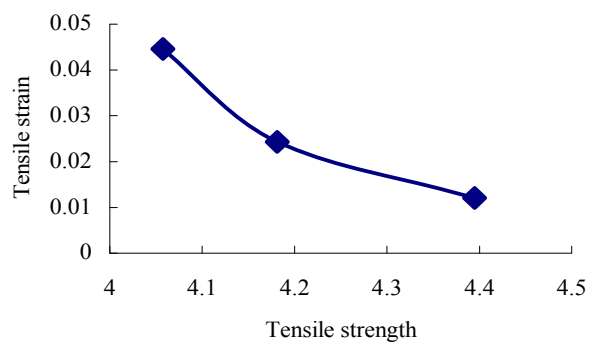

Fig. (6). The relationship between tensile strain and tensile strength.

Where $\sigma_{p, h}$ ultimate tensile strength of HFRCC(SPE), $\varepsilon_{c u, h}$ tensile strain at peak load (ultimate tensile strain) of HFRCC(SPE), $V_{f, P E}, V_{f, s}$ - the volume fraction of PE fiber and steel fiber, respectively, $l_{f, P E}, l_{f, s},-$ the length of PE fiber and steel fiber, respectively, $\phi_{f, P E}, \phi_{f, s}$, - the diameter of PE fiber and steel fiber, respectively, $V_{f}-$ the volume fraction of all fibers.

Calculated and experimentally measured $\varepsilon_{c u, h}$ is tabulated in Table 6. The ratio of experimental to calculated tensile strain at peak load of HFRCC(SPE) ranges between 0.82 and 0.99 with an average value of 0.93 . It shows that the calculated tensile strain at peak load is found to be in good agreement with the experimental results.

Table 6. The calculated value of the tensile strain at peak load.

\begin{tabular}{|c|c|c|c|c|c|c|c|c|c|c|}
\hline$V_{f, P E} / \%$ & $l_{f, P E} / \mathbf{m m}$ & $\phi_{f, P E} / \mathbf{m m}$ & $V_{f, s} / \%_{s}$ & $l_{f, s} / \mathrm{mm}$ & $\phi_{f, s} / \mathbf{m m}$ & $V_{f} / \%$ & $\sigma_{p, h} / \mathbf{M P a}$ & $\varepsilon_{c u, h c}$ & $\varepsilon_{c u, h t}$ & $\varepsilon_{c u, h t} / \varepsilon_{c u, h c}$ \\
\hline 0.5 & \multirow{3}{*}{12} & \multirow{3}{*}{0.039} & 1.5 & \multirow{3}{*}{13} & \multirow{3}{*}{0.16} & 2 & 4.3949 & 0.0296 & 0.0243 & 0.82 \\
\hline 1.3 & & & 0.5 & & & 1.8 & 3.07447 & 0.0397 & 0.03915 & 0.99 \\
\hline 0.5 & & & 0.8 & & & 1.3 & 3.70213 & 0.00925 & 0.00918 & 0.99 \\
\hline
\end{tabular}

note: $\varepsilon_{c u, h c}, \varepsilon_{c u, h t}-$ calculated value and test result of $\varepsilon_{c u}$ for HFRCC(SPE), respectively.

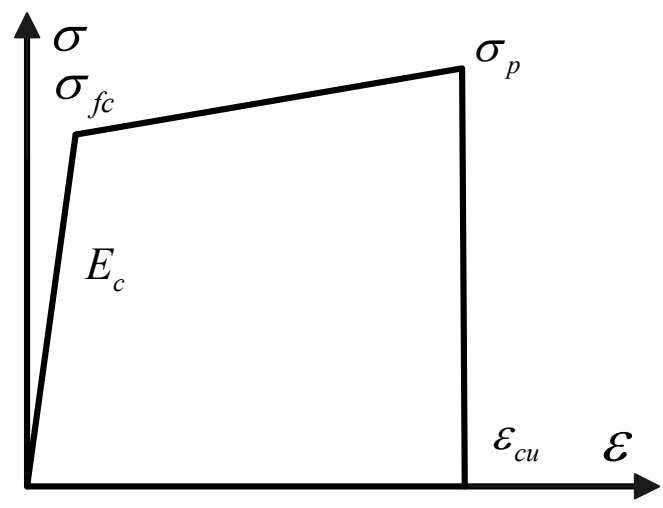

Fig. (7). Tensile stress-strain representation. 


\subsection{Tensile stress-strain curve}

HFRCC(SPE) exhibiting strain hardening and the tensile stress-strain relation for HFRCC(SPE) is characterized by two states, elastic state and strain hardening state. These two states are shown in Fig. (7). The stress-strain relationship is presented by geometric bilinear curve and the formulas of stress strain curve are given as follow:

$$
\sigma(\varepsilon)=\left\{\begin{array}{l}
E_{c} \varepsilon, \quad \varepsilon \leq \sigma_{f c} / E_{c} \\
\sigma_{i}+E_{i e} \varepsilon, \varepsilon>\sigma_{f c} / E_{c}
\end{array}\right.
$$

Where,

$$
E_{i e}=\left(\frac{\sigma_{p}-\sigma_{f c}}{\varepsilon_{c u}-\sigma_{f c} / E_{c}}\right), \sigma_{i}=\sigma_{f c}\left(1-\frac{E_{i e}}{E_{c}}\right) .
$$

The bilinear representation of $\sigma(\varepsilon)$ in formula (12) requires the ultimate strain $\varepsilon_{c u}$, the first crack strength $\sigma_{\mathrm{fc}}$, ultimate tensile stress $\sigma_{\mathrm{p}}$, and composite elastic modulus $E_{c}$. The first crack strength and ultimate tensile of HFRCC(SPE) changes with different volume fractions of PE and steel fibers. In order to use the formula (12) to describe the tensile stress-strain curve for HFRCC(SPE), the formulas of calculating the first crack strength and ultimate tensile strength of HFRCC(SPE) with different volume fractions are presented by fitting the experiment data originating from relative study [14].

$$
\begin{gathered}
\sigma_{f c, h}=a_{1} \sigma_{f c, P E} \\
\sigma_{p, h}=b_{1} \sigma_{p, P E} \\
a_{1}=0.264 \frac{V_{f, P E} l_{f, P E}}{\phi_{f, P E}}+1.566 \frac{V_{f, s} l_{f, s}}{\phi_{f, s}} \\
b_{1}=0.185 \frac{V_{f, P E} l_{f, P E}}{\phi_{f, P E}}+1.129 \frac{V_{f, s} l_{f, s}}{\phi_{f, s}}
\end{gathered}
$$

Where $\sigma_{\mathrm{fc}, \mathrm{h}}, \sigma_{\mathrm{fc}, \mathrm{PE}}-$ the first crack strength of HFRCC (SPE) and PEFRCC, respectively, $\sigma_{\mathrm{p}, \mathrm{h}}, \sigma_{\mathrm{p}, \mathrm{PE}}-$ the ultimate tensile strength of HFRCC (SPE) and PEFRCC, respectively.

Calculated and experimentally measured $\sigma_{\mathrm{fc}, \mathrm{h}}$ and $\sigma_{\mathrm{p}, \mathrm{h}}$ are tabulated in Table 7 . The ratio of experimental to calculate first-crack strength of HFRCC(SPE) ranges between 0.92 and 1.02 with an average value of 0.95 and the ratio of experimental to calculate ultimate strength of HFRCC(SPE) ranges between 0.92 and 0.98 with an average value of 0.94 , the calculated results are found to be in good agreement with the experimental results. To calculate $\sigma_{\mathrm{fc}, \mathrm{h}}$ and $\sigma_{\mathrm{p}, \mathrm{h}}$,

\begin{tabular}{|c|c|c|c|c|c|c|c|c|c|}
\hline$V_{f, P E} / \%$ & $V_{f, s} / \%$ & $\sigma_{f c, P E, t}$ & $\sigma_{p, P E, t}$ & $\sigma_{f c, h, c}$ & $\sigma_{p, h, c}$ & $\sigma_{f c, h, t}$ & $\sigma_{p, h, t}$ & $\sigma_{f c, h, t} / \sigma_{f c, h, c}$ & $\sigma_{p, h, t} / \sigma_{p, h, c}$ \\
\hline 0.2 & 1.5 & \multirow{4}{*}{1.64} & \multirow{4}{*}{2.86} & 3.40 & 4.26 & 3.23 & 4.16 & 0.95 & 0.98 \\
\hline 1.3 & 0.5 & & & 2.78 & 3.43 & 2.56 & 3.15 & 0.92 & 0.92 \\
\hline 0.8 & 1 & & & 3.15 & 3.93 & 3.22 & 3.64 & 1.02 & 0.93 \\
\hline 0.5 & 1.5 & & & 3.80 & 4.75 & 3.41 & 4.41 & 0.90 & 0.93 \\
\hline
\end{tabular}
$\sigma_{\mathrm{fc}, \mathrm{PE}}$ and $\sigma_{\mathrm{p}, \mathrm{h}}$ and $\sigma_{\mathrm{p}, \mathrm{PE}}$ are required, $\sigma_{\mathrm{fc}, \text { PE }}$ and $\sigma_{\mathrm{p}, \text { PE }}$ which can be measured by uni-axial tensile test or calculated by the formulas presented in reference [15]. Supposed $E_{c}$, and $\sigma_{\mathrm{fc}, \text { PE }}$ are $\sigma_{\mathrm{p}, \mathrm{PE}}$ known, and three major parameters, $\varepsilon_{\mathrm{cu}, \mathrm{h}}$, and $\sigma_{\mathrm{fc}, \mathrm{h}}$, $\sigma_{\mathrm{p}, \mathrm{h}}$ can be calculated by formula 13 and 14 . As $\varepsilon_{\mathrm{cu}, \mathrm{h}}, \sigma_{\mathrm{fc}, \mathrm{h}}$, and $\varepsilon_{\mathrm{p}, \mathrm{h}}$ are known, formula 12 can be used to describe the stress-strain curve of HFRCC(SPE).

Table 7. The calculated value of the first crack strength (MPa) and tensile strength (MPa).

note: $\sigma_{\mathrm{fc}, \mathrm{h}, \mathrm{c}}, \sigma_{\mathrm{fc}, \mathrm{h}, \mathrm{t}}-$ calculated value and test result of $\sigma_{\mathrm{fc}, \mathrm{h}}$ for HFRCC(SPE), respectively, $\sigma_{\mathrm{p}, \mathrm{h}, \mathrm{c}}, \sigma_{\mathrm{p}, \mathrm{h}, \mathrm{t}}-$ calculated value and test result of $\sigma_{\mathrm{p}, \mathrm{h}}$ for HFRCC(SPE), respectively.

\subsection{Compressive Stress-strain Curve}

The stress-strain relation of HFRCC(SP) like concrete contains three stages. The first part is linear elastic stage, the stress-strain curve is straight line. The second part is elastoplasticity stage, the stress-strain curve is not straight line but 
curve and the stress increases smoothly. The third stage called strain softening, the stress decreases slowly which does not decrease sharply like normal concrete or high strength concrete. In order to give good predictions of the complete stress-strain relationship of HFRCC(SP), the stress-strain curve is divided into two distinct branches- an ascending and a descending branch. The ascending branch is the part of stress-strain curve before the peak stress and descending branch is strain softening stage. The elastic modulus, compressive strength and peak strain are normally used to characterize the ascending branch. For the descending branch, fibers have important effects on the aspects of confining the developing of cracks and the volume fraction $V_{f}$ and the aspect ratio $l / \phi$ are used to describe the descending branch.

Mansur [16] proposed the modified equation for high-strength fiber concrete. The equation of the ascending branch is given as follows:

$$
\sigma=f_{o}\left[\frac{\beta\left(\frac{\varepsilon}{\varepsilon_{o}}\right)}{\beta-1+\left(\frac{\varepsilon}{\varepsilon_{o}}\right)^{\beta}}\right]
$$

Where,

$$
\beta=\frac{1}{1-\frac{f_{o}}{\varepsilon_{o} E_{i t}}}
$$

where $f_{0}$ - compressive strength; $\varepsilon_{0}$-peak strain; $E_{t i}$ - elastic modulus; $\beta$-material parameter that depends on the shape of the stress-strain diagram.

The equation of the descending branch is given as follows:

$$
\sigma=f_{o}\left[\frac{k_{1} \beta\left(\frac{\varepsilon}{\varepsilon_{o}}\right)}{k_{1} \beta-1+\left(\frac{\varepsilon}{\varepsilon_{o}}\right)^{k_{2} \beta}}\right]
$$

Where,

$$
\begin{aligned}
& k_{1}=\left(\frac{50}{f_{o}}\right)^{3.0}\left[1+2.5\left(\frac{V_{f} l}{\phi}\right)^{2.5}\right] \\
& k_{2}=\left(\frac{50}{f_{o}}\right)^{1.3}\left[1-0.11\left(\frac{V_{f} l}{\phi}\right)^{-1.1}\right]
\end{aligned}
$$

Where $k_{1}$ and $k_{2}$ are parameters that reflect the effect of fibers and cater for the residual stress. $V_{f}-$ volume fraction (\%) of fiber; $l / \phi$ - length and diameter ( $\mathrm{mm})$ of fiber.

Compared with the other equations, equation (17-20) are more simple, considering the effect of fiber and suitable to describe the high-strength fiber concrete with 70-120MPa. From the analysis of the present set of test data, equations (17-18) give good predictions of the ascending branch of stress-strain curve. From Fig. (8a), the descending branch of test curve has large difference with equation (19-20). For HFRCC(SP) material, it consists of two fibers, but equations (19-20) only consider the effect of one kind of fiber. The sharpness of the descending branch depends on $k_{1}$ and $k_{2}$, modified them to give a good description of descending branch of HFRCC(SP). Based on the experimental data, following equations are obtained:

$$
k_{1}{ }^{\prime}=\left(\frac{50}{f_{o}}\right)^{4.0}\left[1+2.0\left(\left(\frac{V_{f, s} l_{f, s}}{\phi_{f, s}}\right)^{2.0}+\left(\frac{V_{f, p} l_{f, p}}{\phi_{p}}\right)^{-6.0}\right)\right]
$$




$$
k_{2}{ }^{\prime}=\left(\frac{50}{f_{o}}\right)^{-1.6}\left[1-1.5\left(\left(\frac{V_{f, s} l_{f, s}}{\phi_{f, s}}\right)^{5.6}+\left(\frac{V_{f, p} l_{f, p}}{\phi_{f, p}}\right)^{-6.4}\right)\right]
$$

Where $V_{f, p}$-the volume fractions of PVA fiber, $l_{f, p}, \phi_{f, p}$-the length and diameter of PVA fiber, respectively.

The test curves and the equations (17-19) and (21) are shown in Fig. (8). Note that the stresses and strains have been normalized (with respect to its peak stress and strain), it is obvious that the modified formulas give a good predictions of stress-strain curve of $\mathrm{HFRCC}(\mathrm{SP})$.

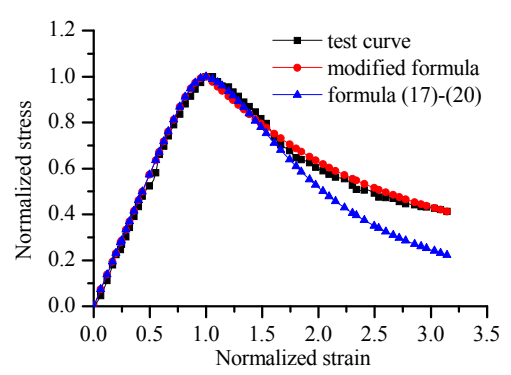

(a) Specimen NO.1

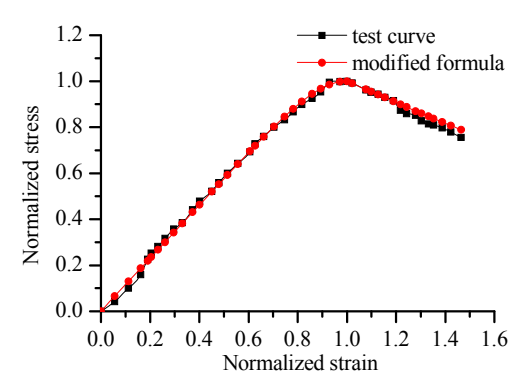

(b) Specimen NO.2

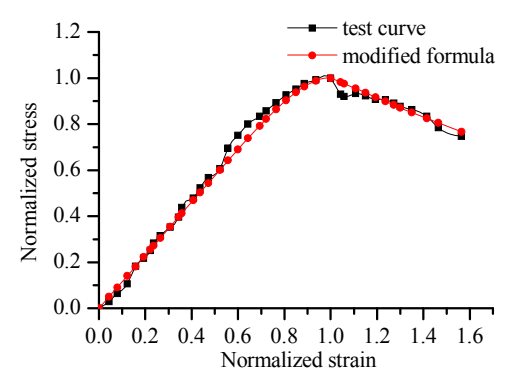

(c) Specimen NO.3

Fig. (8). Comparison between measured curves of cylinder specimens and modified formulas.

\section{CONCLUSION}

Based on compressive and tensile tests of HFRCC and the analysis of the experimental results of the related literature, the followings can be concluded.

1. Steel fibers can reinforce the tensile strength more obviously than the compressive strength of HFRCC(SP). HFRCC(SP) processes higher tensile strength than ECC. PVA fibers can improve the compressive peak stain more significant than steel fibers.

2. The modified formulas are proposed to calculate the peak strain, elastic modulus and tensile strength.

3. The relationship between tensile strain at peak load and tensile strength of HFRCC (SPE) are presented, it is convenient to use formulas(5) (11) to calculate the tensile strain at peak load.

4. The tensile stress-strain curve formulas describing the stress-strain relationship of HFRCC(SPE) with different 
volume fractions of fibers are proposed.

5. The parameters $k_{1}$ and $k_{2}$ of stress-strain curve formulae for the HSFC presented by Mansur are modified, the modified formulas have a good description of the stress-strain curve of the HFRCC(SP) and the formulas can predict the compressive stress-strain relation of HFRCC(SP) with different fiber fractions.

\section{CONFLICT OF INTEREST}

The authors confirm that this article content has no conflict of interest.

\section{ACKNOWLEDGEMENTS}

This study was supported by State Key Lab of Subtropical Building Science, South China University of Technology (No. 2012KB28).

\section{REFERENCES}

[1] V.C. Li, H.C. Wu, M. Maalej, D.K. Mishra, and T. Hashida, "Tensile behavior of engineered cementitious composites with discontinuous random steel fibers", J. Am. Ceram. Soc., vol. 79, no. 1, pp. 74-78, 1996. [http://dx.doi.org/10.1111/j.1151-2916.1996.tb07882.x]

[2] M. Maalej, T. Hashida, and V.C. Li, "Effect of fiber volume fraction on the off-crack-plane fracture energy in strain-hardening engineered cementitious composites", J. Am. Ceram. Soc., vol. 78, no. 12, pp. 3369-3375, 1995. [http://dx.doi.org/10.1111/j.1151-2916.1995.tb07979.x]

[3] V.C. Li, "On engineered cementitious composites (ECC)", J. Adv. Conc. Technol., vol. 1, pp. 215-230, 2003.

[4] S. Ahmed, and M. Maalej, "Tensile strain hardening behaviour of hybrid steel-polyethylene fibre reinforced cementitious composites", Constr. Build. Mater., vol. 23, pp. 96-106, 2003. [http://dx.doi.org/10.1016/j.conbuildmat.2008.01.009]

[5] V.W. Lin, S.T. Quek, M.P. Nguyen, and M. Maalej, "Strengthening of masonry walls using hybrid-fiber engineered cementitious composite", J. Compos. Mater., vol. 44, no. 8, pp. 1007-1029, 2010. [http://dx.doi.org/10.1177/0021998309346186]

[6] M. Maalej, S.T. Quek, and J. Zhang, "Behavior of hybrid-fiber engineered cementitious composites subjected to dynamic tensile loading and projectile impact", J. Mater. Civ. Eng., vol. 17, pp. 143-152, 2005. [http://dx.doi.org/10.1061/(ASCE)0899-1561(2005)17:2(143)]

[7] H.X. Yang, J. Li, and Y.S. Huang, "Study on the mechanical properties of high performance hybrid fiber reinforced cementitious composite (HFRCC) under impact loading", Key Eng. Mater., vol. 629-630, pp. 79-84, 2014. [http://dx.doi.org/10.4028/www.scientific.net/KEM.629-630.79]

[8] H.X. Yang, Y.S. Huang, and J. Li, "Study on dynamic mechanical properties of hybrid fiber reinforced cementitious composites", J. South Chin. Uni. Technol., vol. 43, no. 7, pp. 50-56, 2015. [Natural Science Edition].

[9] M.D. Lepech, V.C. Li, R.E. Robertson, and G. Keoleian, "Design of green engineered cementitious composites for improved sustainability", ACI Mater. J., vol. 105, no. 6, pp. 567-575, 2008.

[10] Commission for the European Communities, "Eurocode 2: design of concrete structures-Part 1: general rules and rules for buildings", In: EN 1992-1-1, Brussels, Belgium, 2005.

[11] ACI Committee 363, State-of-the-Art Report on High-Strength Concrete., American Concrete Institute: Farmington Hills, Mich., 1992.

[12] CEB-FIP MC 90, Design of Concrete Structures, CEB-FIP Model-Code 1990, Thomas Telford, 1993.

[13] Design Consideration for Steel Fiber Reinforced Concrete., Farmington Hills, Mich., 1999.

[14] S. Ahmed, M. Maalej, and P. Paramasivam, "Analytical model for tensile strain hardening and multiple cracking behavior of hybrid fiberengineered cementitious composites", Electron. Notes Theor. Comput. Sci., vol. 64, no. 4, pp. 73-94, 2007.

[15] V.C. Li, and C.K. Leung, "Steady-state and multiple cracking of short random fiber composites", J. Eng. Mech., vol. 118, no. 11, pp. 2246-2264, 1992. [J].

[http://dx.doi.org/10.1061/(ASCE)0733-9399(1992)118:11(2246)]

[16] M.A. Mansur, M.S. Chin, and T.H. Wee, "Stress-strain relationship of high-strength fiber concrete in compression", J. Mater. Civ. Eng., vol. 11, pp. 21-29, 1999.

[http://dx.doi.org/10.1061/(ASCE)0899-1561(1999)11:1(21)] 